\title{
MECHANICAL PROPERTIES OF ROCK UNITS FROM THE POMPEII ARCHAEOLOGICAL SITE, ITALY
}

\author{
FRANCESCA AUTIERO, GIUSEPPINA DE MARTINO, MARCO DI LUDOVICO \& ANDREA PROTA \\ Department of Structures for Engineering and Architecture, University of Naples Federico II, Italy
}

\begin{abstract}
The definition of compatible conservation interventions on the archaeological built asset requires a comprehensive knowledge of physical, chemical and mechanical properties of the ancient masonry structures and their components. However, information on the mechanical properties of units, mortars and masonry assemblages are still lacking especially with reference to one of the most popular UNESCO World Heritage Sites in Italy, the Pompeii archaeological site. Thus, the paper focuses on the mechanical characterization of original rock specimens collected within the new archaeological excavation work area in Regio V of the Pompeii site. Ultrasonic pulse velocity tests (UPV) and Schmidt hammer rebound test were carried out on ten units of three different rock types: three travertine, five lava and two foam lava (i.e. "calcare del Sarno", "lava" and "cruma"). Then, UPV were carried out on 51 cubic specimens obtained from the cut of the units, both at ordinary moisture content and after drying. Finally, uniaxial compression tests were carried out on 32 cubic specimens. In the following, the results of non-destructive tests are discussed and compared with those provided by destructive tests in terms of compressive strength.
\end{abstract}

Keywords: rock units, masonry structures, Pompeii archaeological site, mechanical properties, nondestructive tests, destructive tests.

\section{INTRODUCTION}

In order to protect both the tangible and the intangible asset in the Pompeii archaeological site, restoration interventions of masonry structures must comply with the principles of compatibility, reversibility, distinguishability and minimum intervention. To this aim, an interdisciplinary approach to the knowledge of the archaeological built asset is needed for the investigation of physical, chemical and mechanical properties of ancient masonry structures and their components (mortars and units) [1]. In particular, information on the mechanical properties of mortars and units is required both for the structural assessment of the ancient structures and for the choice of suitable materials and techniques for restoration interventions [2], [3]. However, from the structural point of view, data related to building materials in the Pompeii archaeological site are still limited [4].

Concerning the investigation of the mechanical properties of rock units, it can be carried out both in laboratory and in situ by means of destructive tests (DTs) and non-destructive tests (NDTs). However, DTs are not allowed in the archaeological field for conservation reasons and available data provided by NDTs, are still limited. Indeed, NDTs on the archaeological structures are sustainable in terms of: (i) conservation of the built asset; (ii) moderate cost; and (iii) relatively short implementation [5]. NDTs provide an indirect estimation of the material strength based on empirical correlations. However, such correlations depend on the rock type and the test conditions and they should be calibrated on the outcomes of destructive tests [5], [6]. Among NDTs, the most common methods for the characterization of building materials from existing structures are the ultrasonic pulse velocity test (UPV), and the Schmidt hammer rebound test (SHR) [5]-[9]. In UPV the velocity of propagation of longitudinal stress wave pulses through the specimen is evaluated. The pulse is generated by an electro-acoustical transducer and received by a second transducer. The propagation time of the pulse is electronically recorded and the path length 
is measured, thus, the pulse velocity $V$ is calculated. UPV can be used to assess the uniformity of the specimen and the presence of defects or anomalies, other than to estimate the strength and the elastic properties of the tested material [10]-[13]. SHR measures the rebound of a spring-loaded piston that strikes a hammer in contact with the surface of the specimen. The test equipment records the rebound distance in terms of a rebound number, $H_{r}$, which depends on the hardness of the tested material. From the rebound number it is possible to obtain a rapid classification of the tested material and an indirect estimation of its strength by means of conversion charts [14]-[17]. Both UPV and SHR were firstly developed for the assessment of concrete structures [10], [11], [15], [16], [18], then they were calibrated and standardized for rock specimens [12], [13], [17]. Other methods were developed based on a combined use of UPV and SHR, with the aim of obtaining a more reliable estimation of the material strength [15], [18]. Technical literature presents many empirical correlation of UPV and SHR results with mechanical and physical properties of rock specimens (i.e. compressive strength (UCS), Young's modulus $(E)$, dynamic modulus of elasticity $\left(E_{d}\right)$ dynamic Poisson's ratio $\left(v_{d}\right)$ density $(\rho))$ [5]-[9]. However, specific experimentation on the traditional rock types used in the ancient building techniques in the Pompeii site, are still needed.

To fill such gap, in this paper mechanical properties of rock units from ancient masonry structures in Pompeii archaeological site are investigated by means of both NDTs (UPV and SHR) and uniaxial compression test. Ten rock units of three different rock types were collected within the new archaeological excavation work area in Regio V: three travertine units, five lava units and two foam lava units (i.e. "calcare del Sarno", "lava" and "cruma"). UPV and SHR were carried out on the units, and then UPV were carried out on 51 cubic specimens obtained from the units at ordinary moisture content and after drying. Finally, uniaxial compression tests were carried out on 32 cubic specimens. In the following, the experimental outcomes of NDTs on the units and on the cubic specimens are presented and compared with the results of DTs in terms of compressive strength.

\section{ROCK UNITS FROM POMPEII SITE}

From May 2018, new archaeological excavation work was initiated in the Regio V of Pompeii archaeological site (Fig. 1).

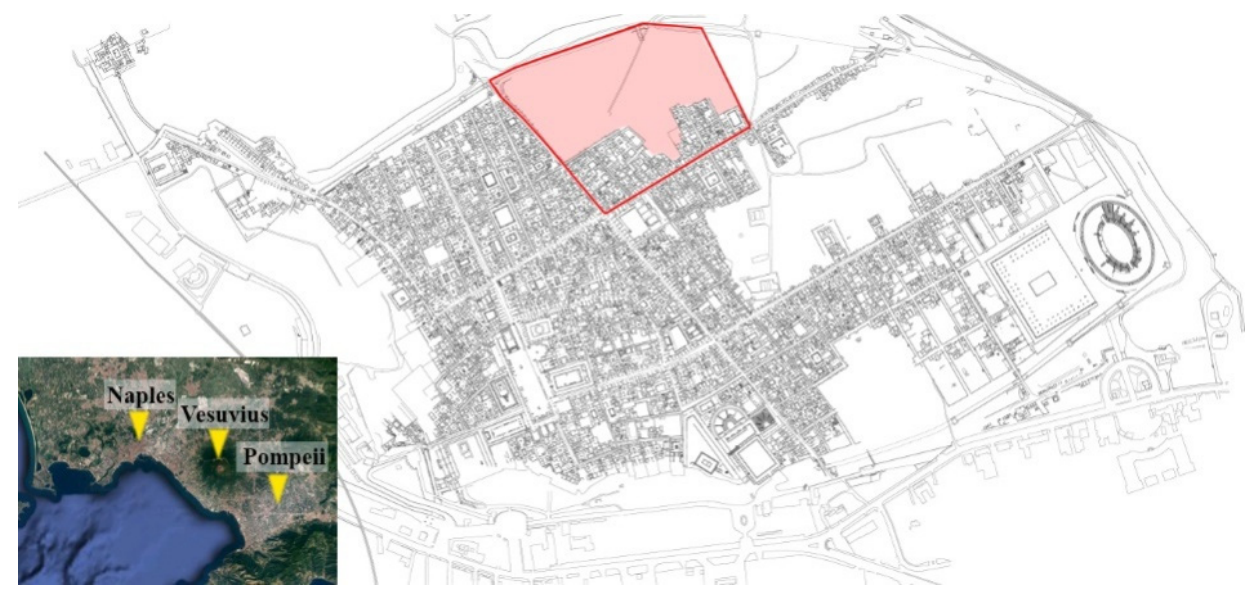

Figure 1: Location of Pompeii near the city of Naples and Vesuvius and plan of Pompeii archaeological site with the indication of the Regio V borders (red line) and the new archaeological excavation work area in the Regio V (red area). 
Ten rock units of three different rock types were collected within the work area: three travertine units, five lava units and two foam lava units.

Travertine is a carbonate rock generated from the precipitation of calcium carbonate in the Sarno river, traditionally named in the site "calcare del Sarno". Travertine units were whitish coloured and presented a cavernous fabric with many cavities left from the dissolution of plant materials and microorganisms [19]. It was one of the oldest building material used in the ancient Pompeii city, since the 6th-5th century BC. Easy to cut, it was widely used for the realization of masonry structures in the form of: rubbles for the opus incertum, small blocks for the opus vittatum mixtum, large blocks for the opus africanum and for the realization of window frames and door jambs [20]-[22]. Lava is an effusive rock derived from the volcanic bedrock of the ancient Pompeii city. Two main types of lava were used in the ancient masonry structures within the site: leucite phonolitic tephrite and trachyte [19]. Both types present a porphyritic structure with significant phenocrysts. The collected lava units were dark grey coloured, scoriaceous, glass-rich, with two type of phenocrysts: mostly black and of elongated shape phenocrysts (augite) and white and of rounded shape phenocrysts (leucite). Hard and compact, lava was mainly used in the ancient Pompeii in the form of rubbles for the opus incertum, sometimes with higher concentration in the lower part of the walls where a greater strength was needed, or in the spaces marked by higher moisture conditions, for its compactness. It was also used for the realization of doorsteps and flagstones [20]-[22]. Foam lava, traditionally named in the site "cruma", is a subtype of tephrite [19]. It presented high porous texture, with more or less large rounded vesicles and dark red to grey colour. Lightweight and easy to cut, it was commonly used in the form of small-size units for the realization of masonry structures (rubbles for the opus incertum, small blocks for the opus vittatum mixtum and opus reticulatum) [20]-[22].

The collected units were named by an alphanumeric code made by the initials of the traditional name of the rock type (CS, L, CR) and a serial number: CS1, CS2, CS3, L1, L2, L3, L4, L5, CR1 and CR2. Standard cubic specimens $70 \mathrm{~mm} \times 70 \mathrm{~mm} \times 70 \mathrm{~mm}$ were realized from the units, according to [23]. Fifty-one specimens were obtained: four specimens from CS1; five specimens from CS2; four specimens from CS3; two specimens from L1; two specimens from L2; five specimens from L3; four specimens from L4; one specimen from L5; four specimens from CR1; 20 specimens from CR2. Each cubic specimen was named by adding a further serial number to the name of the unit of origin (i.e. CS1.1, CS1.2, CS1.3, and CS1.4).

\section{ULTRASONIC PULSE VELOCITY TEST AND SCHMIDT HAMMER TEST}

UPV were carried out by means of the "MAE I-SONIC" apparatus. It allowed obtaining the propagation time and the transmission velocity of longitudinal compression wave pulses through the specimen and visualizing the acquired data on a graphic display. Transducers of natural resonance frequency of $53 \mathrm{kHz}$ were used. Compression wave velocities, $V$, were obtained in direct transmission. Coupling material was used between the specimen and each transducer in order to guarantee an adequate acoustical coupling. UPV were carried out on the units at ordinary moisture content first, thus, after the cut of the units, UPV were carried out on the cubic specimens at ordinary moisture content and after drying. Concerning UPV on the units, compression wave velocities were evaluated as the average of three measurements obtained along a single direction. The transducers were fit to the irregular shape of each unit in order to ensure their alignment for the direct transmission and avoid local defects or fractures. For each unit the distance between the transducers was recorded for the computation of the compression wave velocity. Note that it was not possible to collect data for two units, L2 and L4, probably due to the presence of cracks or voids inside the 
tested materials. Concerning UPV on the cubic specimens both at ordinary moisture content and after drying, compression wave velocities were evaluated in two orthogonal directions, each of them calculated as the average of three measurements. UPV on the cubic specimens were carried out at ordinary moisture content first, then UPV were repeated on the specimens after drying at a temperature of $70 \pm 5^{\circ} \mathrm{C}$ to constant mass according to [13]. Table 1 reports the number of cubic specimens obtained from each unit, $n_{s}$, and the average density of the cubic specimens obtained from each unit at ordinary moisture content, $\rho$, and the bulk density, $\rho_{\mathrm{d}}$. The density at ordinary moisture content and the bulk density were calculated for each cubic specimen as the ratio between its mass, at ordinary moisture content and at after drying respectively, and its volume.

Table 1: Average density at ordinary moisture content and average bulk density of the cubic specimens obtained from each unit.

\begin{tabular}{|c|c|c|c|c|c|}
\hline Unit (-) & $\mathbf{n}_{\mathbf{s}}(\mathbf{-})$ & $\boldsymbol{\rho}\left(\mathbf{k g} / \mathbf{m}^{\mathbf{3}}\right)$ & $\mathbf{C o V}$ & $\boldsymbol{\rho}_{\boldsymbol{d}} \mathbf{( \mathbf { k g } / \mathbf { m } ^ { \mathbf { 3 } } )}$ & $\mathbf{C o V}$ \\
\hline $\mathbf{L 1}$ & 2 & 2,305 & $2 \%$ & 2,286 & $3 \%$ \\
\hline $\mathbf{L 2}$ & 2 & 2,161 & $2 \%$ & 2,146 & $2 \%$ \\
\hline $\mathbf{L 3}$ & 5 & 2,347 & $1 \%$ & 2,345 & $1 \%$ \\
\hline $\mathbf{L 4}$ & 4 & 2,252 & $2 \%$ & 2,247 & $2 \%$ \\
\hline $\mathbf{L 5}$ & 1 & 2,096 & - & 2,061 & - \\
\hline CS1 & 4 & 1,237 & $4 \%$ & 1,128 & $4 \%$ \\
\hline CS2 & 5 & 1,395 & $2 \%$ & 1,387 & $2 \%$ \\
\hline CS3 & 4 & 1,667 & $7 \%$ & 1,556 & $10 \%$ \\
\hline CR1 & 4 & 982 & $8 \%$ & 965 & $9 \%$ \\
\hline CR2 & 20 & 963 & $7 \%$ & 933 & $8 \%$ \\
\hline
\end{tabular}

Schmidt hammer tests, SHR, were carried out on the units by means of a low impact energy hammer, $L$-type [14]. For the execution of SHR, each unit was stuck in a clamp and the hammer was positioned horizontally. The rebound distance of the piston was visualized on a linear scale on the instrument and recorded to the nearest whole number. According to [17], ten values of the rebound number were recorded for each unit in different locations on the specimen surface, separated by at least the diameter of the piston. Thus, readings differing more than seven units from the average of the ten recorded values were rejected and $H_{r}$ was evaluated as the average of the remaining values. Note that data were not recorded for units CS1 and L4, as local rupture occurred on the specimens' surface during the rebound testing, so the tests were rejected.

Figs 2 and 3 summarize the experimental outcomes of NDTs on the units and on the cubic specimens, respectively. In particular, Fig. 2 reports the compression wave velocity $V$ and the rebound number $H_{r}$ for each unit. From UPV on the units, it resulted that the maximum velocity values were recorded on travertine units, with an average velocity $V=2,350 \mathrm{~m} / \mathrm{s}$. As far as lava units were concerned, it resulted in an average velocity $V=1,616 \mathrm{~m} / \mathrm{s}$ while the foam lava had an average velocity $V=1,320 \mathrm{~m} / \mathrm{s}$. From the SHR tests on the units, lava units resulted as those with the maximum rebound number $H_{r}=29$ while foam lava units and travertine units had $H_{r}=15$ and $H_{r}=17$, respectively. Fig. 3 reports the average velocities (from test in two orthogonal directions) obtained by UPV on the cubic specimens. In particular, the results at ordinary moisture content and after drying are reported in Fig. 3(a) and (b), respectively. For both the UPV on the cubic specimens, the trend of velocities is similar to that of UPV on the units. 


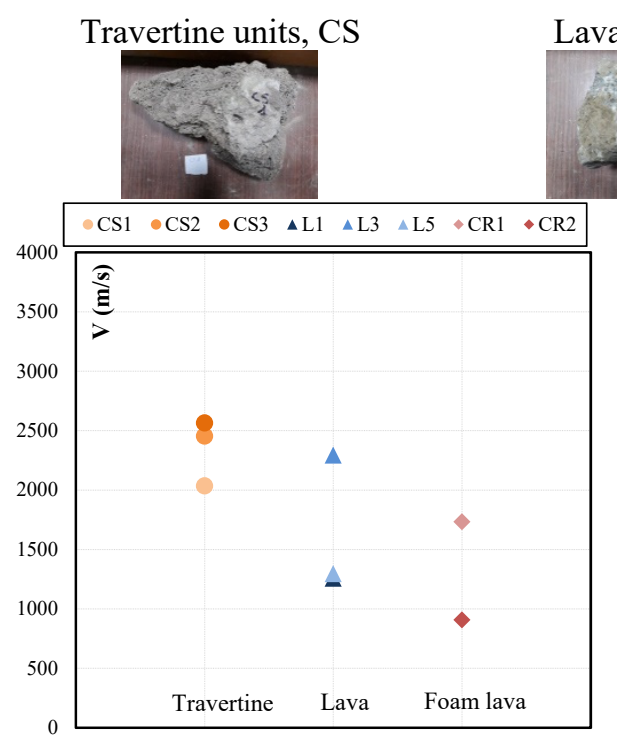

(a)
Lava units, $\mathrm{L} \quad$ Foam lava units, $\mathrm{CR}$
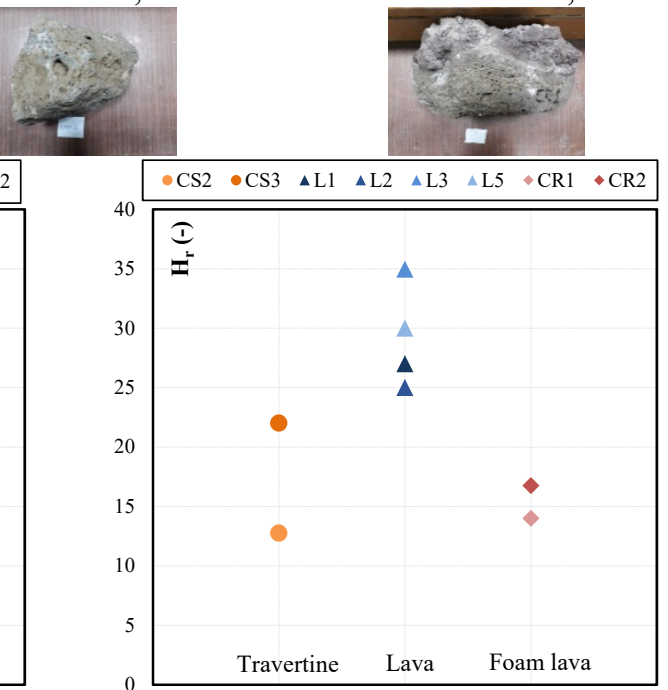

(b)

Figure 2: NDTs results for the rock units. (a) Ultrasonic pulse velocity tests (UPV); and (b) Schmidt hammer tests (SHR).

Travertine cubic specimens,

$\mathrm{CS}$

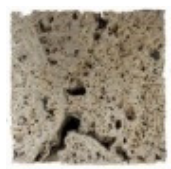

Lava cubic specimens, L

Foam lava cubic specimens,

$\mathrm{CR}$

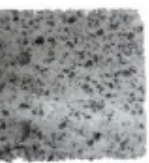

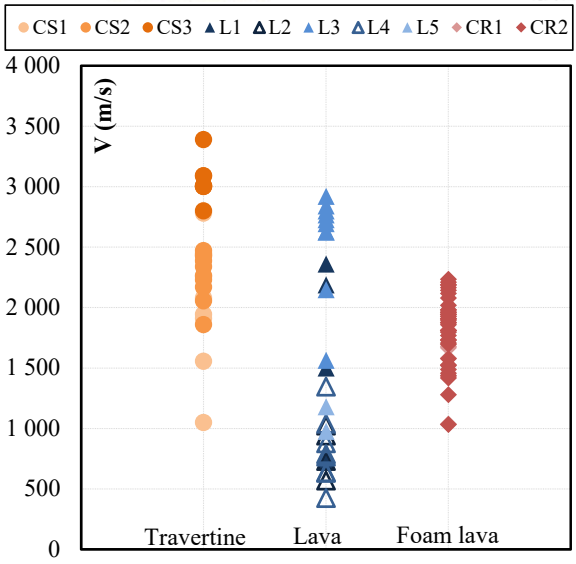

(a)

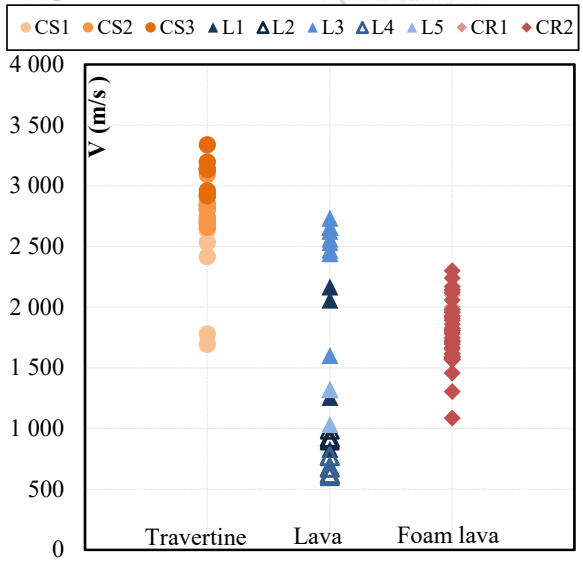

(b)

Figure 3: Ultrasonic pulse velocity tests (UPV) results for the cubic specimens obtained from each unit. (a) Ordinary moisture content; and (b) Dried condition. 


\section{COMPRESSION TESTS}

Uniaxial compression tests were carried out on the cubic specimens according to [23]. For the correlation of the uniaxial compression strength with the ultrasonic pulse velocity, UPV were repeated on the cubic specimens before the execution of DTs along the direction of the compression load, $z$, and $V_{z}$ was evaluated as the average of three records. Uniaxial compression tests were carried out under displacement control at a constant velocity $0.01 \mathrm{~mm} / \mathrm{s}$. During the tests, the vertical shortening was measured by means of linear variable displacement transducers (LVDTs) (Fig. 4).

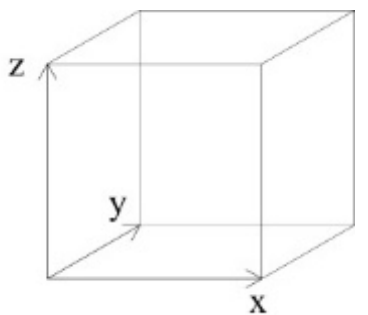

(a)

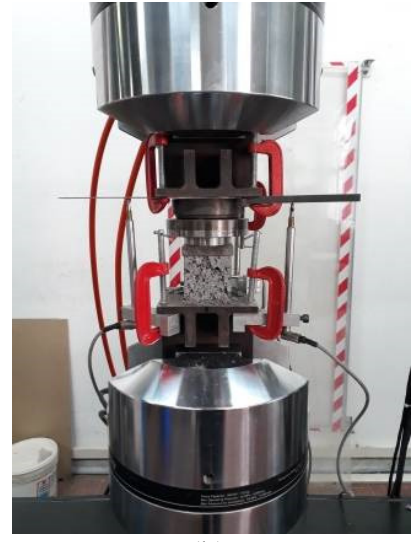

(b)

Figure 4: (a) Reference system for cubic specimens; and (b) Compression test set up.

The test program involved 32 specimens: 11 travertine specimens, eight lava specimens and 13 foam lava specimens. The uniaxial compression tests results showed a great variability of behaviour for each of the three rock types, due to the great heterogeneity proper to the materials and due to the mechanical and physical decay of each unit. Lava specimens showed the maximum compressive strength, with an average value $\sigma_{z}=38.43 \mathrm{MPa}(\mathrm{CoV}=40 \%)$ and foam lava showed the minimum strength, with an average value $\sigma_{z}=3.90 \mathrm{MPa}(\mathrm{CoV}=35 \%)$. Finally travertine showed relatively low values of strength and a more significant variability, with an average value $\sigma_{z}=5.88 \mathrm{MPa}(\mathrm{CoV}=75 \%)$. In particular, Concerning the travertine, specimens obtained from unit CS3 (CS3.1, CS3.2, CS3.3) they showed the highest values (respectively, $\sigma_{z}=7.32,10.24$ and $16.70 \mathrm{MPa}$ ). The experimental axial stress-axial strain relationships for each rock type are reported in Fig. 5. After the achievement of the maximum compressive stress, each curve showed a decreasing "softening" branch. The failure of each specimen was conventionally assumed at $80 \%$ of the maximum stress as shown in Fig. 5.

Fig. 6 reports the correlations between the DTs and NDTs outcomes. In particular, Fig. 6(a) reports the correlation between the uniaxial compressive strength along direction $z$ of each tested cubic specimens, $\sigma_{z}$, and the parameter $V_{z} \cdot \rho$, where $V_{z}$ is the ultrasonic pulse velocity evaluated along the direction of the compression load and $\rho$ is the density of the specimen evaluated before the execution of the DTs. The figure shows a good correlation, $R^{2}=0.7493$. Fig. 6 (b) reports the correlation between the uniaxial compressive strength evaluated along the direction $z$ of each tested cubic specimens, $\sigma_{z}$, and the rebound number evaluated on the corresponding unit, $H_{r}$. A good matching between analytical formulation and experimental results were found also in this case, $R^{2}=0.8038$. 


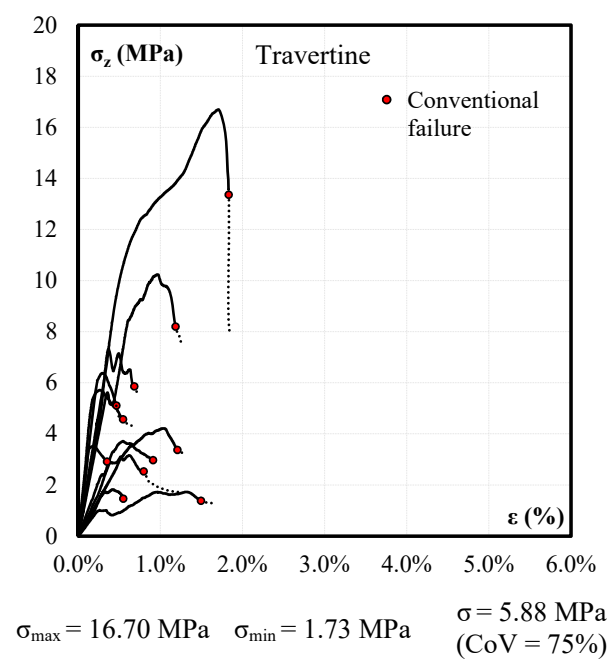

(a)

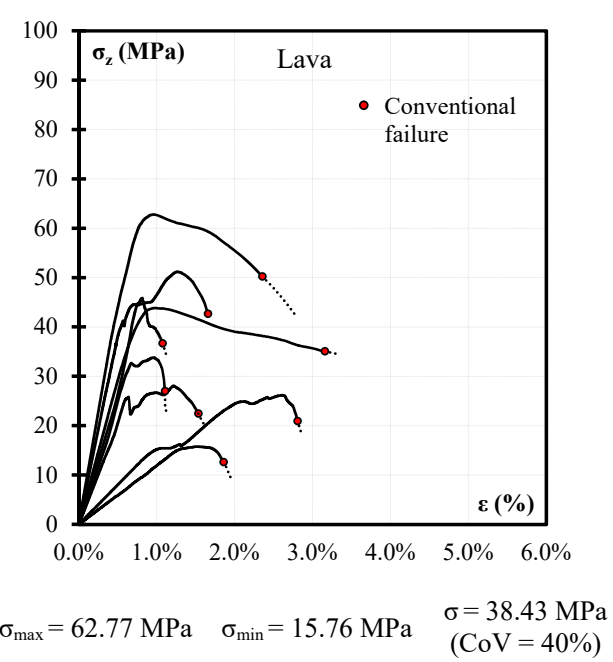

(b)

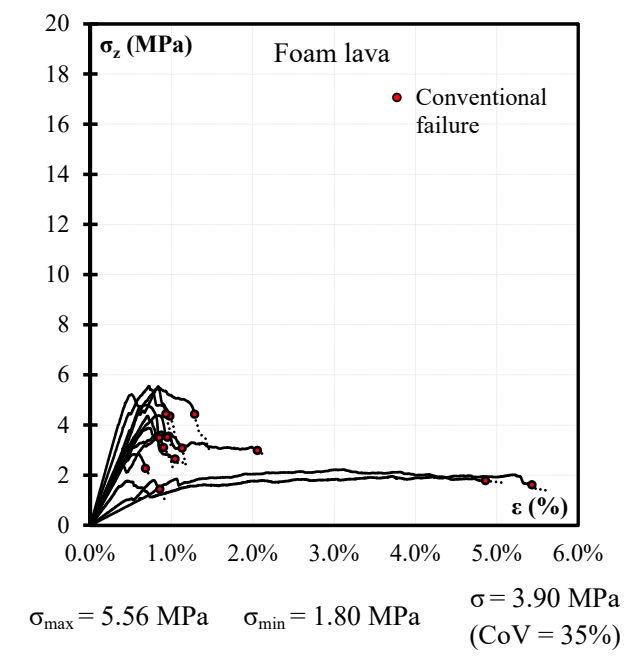

(c)

Figure 5: Axial stress-axial strain relationship. (a) Travertine cubic specimen; (b) Lava cubic specimen; and (c) Foam lava cubic specimen.

\section{CONCLUSIONS}

The mechanical properties of original rock units from the archaeological Pompeii site were investigated by means of the UPV and the SHR. UPV and SHR were carried out on ten units of three different rock types (travertine, lava and foam lava). Then, 51 cubic specimens were obtained from the units and UPV were carried out on them both at ordinary moisture content and after drying. Finally, uniaxial compression tests were carried out on 32 cubic specimens and the results were compared with the experimental outcomes of NDTs. The tests showed that: 


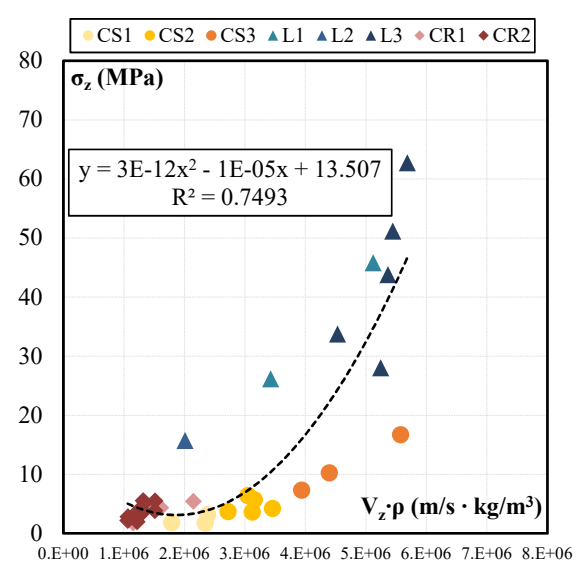

(a)

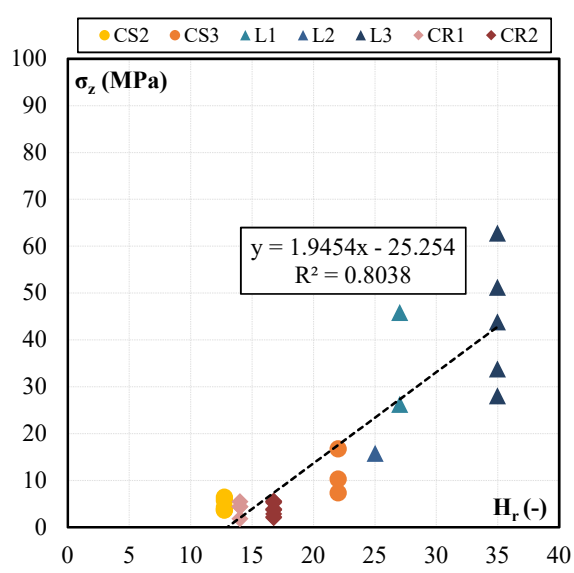

(b)

Figure 6: Correlations between the DTs and NDTs outcomes. (a) Correlation between the uniaxial compressive strength evaluated along the direction $z, \sigma_{z}$, and the parameter $V_{z} \cdot \rho$, where $V_{z}$ is the ultrasonic pulse velocity evaluated along the direction $z$ and $\rho$ is the density of the specimen evaluated before the execution of the DTs; and (b) Correlation between the uniaxial compressive strength evaluated along the direction $z, \sigma_{z}$, and the Schmidt hammer rebound on the units, $H_{r}$.

- The rock types showed a great variability in terms of compressive strength due to the great heterogeneity of the material and to the mechanical and physical decay;

- The maximum compressive strength was obtained on lava cubic specimens;

- Travertine showed an average compressive strength $\sigma_{z}=5.88 \mathrm{MPa}(\mathrm{CoV}=75 \%)$, average rebound number $H_{r}=17$, and an average ultrasonic pulse velocity along the direction of the compression load $V_{z}=2,315 \mathrm{~m} / \mathrm{s}(\mathrm{CoV}=19 \%)$;

- Lava units showed an average compressive strength $\sigma_{z}=38.43 \mathrm{MPa}(\mathrm{CoV}=40 \%)$, average rebound number $H_{r}=29$, and an average ultrasonic pulse velocity along the direction of the compression load $V_{z}=1,987 \mathrm{~m} / \mathrm{s}(\mathrm{CoV}=26 \%)$;

- Foam lava units showed an average compressive strength $\sigma_{z}=3.90 \mathrm{MPa}(\mathrm{CoV}=$ $35 \%$ ), average rebound number $H_{r}=15$, and an average ultrasonic pulse velocity along the direction of the compression load $V_{z}=1,531 \mathrm{~m} / \mathrm{s}(\mathrm{CoV}=13 \%)$;

- Analytical expressions were found to correlate the uniaxial compressive strength with the parameter $V_{z} \cdot \rho$ and the uniaxial compressive strength with the rebound number $H_{r}$; a good matching between analytical formulation and experimental results were found: $R^{2}=0.7493$ for the correlation between $\sigma_{z}$ and $V_{z} \cdot \rho, R^{2}=0.8038$ for the correlation between $\sigma_{z}$ and $H_{r}$.

The tests results could represent a sound tool to provide preliminary information on the mechanical properties of traditional rock types commonly found in archaeological sites of the Roman age. 


\section{ACKNOWLEDGEMENTS}

The authors are grateful for the support and the supervision on the research project provided by the director of Parco Archeologico di Pompei (PAP), Professor Massimo Osanna; the Project Manager of the work in Regio V, Architect Annamaria Mauro; the Managers of the Laboratorio di Ricerche Applicate of PAP, Architect Bruno De Nigris and Dr Alberta Martellone; the Director of the work in Regio V, Architect Gianluca Vitagliano and Engineer Vincenzo Calvanese, member of the Technical Secretariat of the Great Pompeii Project.

\section{REFERENCES}

[1] ICOMOS, Recommendations for the analysis, conservation and structural restoration of architectural heritage. International Scientific Committee for Analysis and Restoration of Structures of Architectural Heritage, Paris, 2001.

[2] Min. BB.AA.CC., Linee Guida per la valutazione e riduzione del rischio sismico del patrimonio culturale con riferimento alle norme tecniche per le costruzioni (D.M. 14 gennaio 2008), Supplemento ordinario alla G.U. n. 54 del 26 febbraio 2011. (In Italian.)

[3] De Nigris, B. \& Previti, M., L'affidabilità strutturale degli interventi di messa in sicurezza del patrimonio archeologico. IF CRASC'17, IV Convegno di Ingegneria Forense, VII Convegno su CRolli, Affidabilità Strutturale, Consolidamento, eds N. Augenti \& L. Jurina, Milan, 14-16 September, 2017.

[4] Autiero, F., De Martino, G., Di Ludovico, M. \& Prota, A., Mechanical behavior of ancient mortar specimens from Pompeii site. COMPDYN 2019, 7th ECCOMAS Thematic Conference on Computational Methods in Structural Dynamics and Earthquake Engineering, eds M. Papadrakakis \& M. Fragiadakis, Crete, 24-26 June, 2019.

[5] Vasanelli, E., Calia, A., Colangiuli, D., Miceli, F. \& Aiello, M.A., Assessing the reliability of non-destructive and moderately invasive techniques for the evaluation of uniaxial compression strength of stone masonry units. Construction and Building Materials, 124, pp. 575-581, 2016. DOI: 10.1016/j.conbuildmat.2016.07.130.

[6] Christaras, B., Non-destructive methods for investigation of some mechanical properties of natural stones in the protection of monuments. Bulletin of the International Association of Engineering Geology, 54, p. 59, 1996.

DOI: $10.1007 / \mathrm{BF} 02600697$.

[7] Yasar, E. \& Erdogan, Y., Correlating sound velocity with density, compression strength and Young modulus of carbonate rocks. International Journal of Rock Mechanics and Mining Sciences, 41(5), pp. 871-875, 2004.

[8] Vasconcelos, G., Lourenco, P.B., Alves, C.A.S. \& Pamplona, J., Ultrasonic evaluation of the physical and mechanical properties of granites. Ultrasonics, 48, pp. 453-466, 2008. DOI: 10.1016/j.ultras.2008.03.008.

[9] Moradian, Z.A. \& Behnia M., Predicting the uniaxial compression strength and static Young's modulus of intact sedimentary rocks using the ultrasonic test. Int. J. Geomech., 9(1), pp. 14-19, 2009.

https://ascelibrary.org/doi/abs/10.1061/(ASCE)1532-3641(2009)9:1(14).

[10] ASTM C597-02, Standard test method for pulse velocity through concrete, ASTM International, West Conshohocken, PA, 2002.

[11] UNI EN 12504-4, Testing concrete: Determination of pulse velocity, 2005.

[12] ASTM D2845-08, Standard test method for laboratory determination of pulse velocities and ultrasonic elastic constants of rock, ASTM International, West Conshohocken, PA, 2017. 
[13] UNI EN 14579, Natural stone test methods: Determination of sound speed propagation, 2005.

[14] RILEM Recommendation MS.D.2, Determination of masonry rebound hardness. Materials and Structures, 31, pp. 363-377, 1998.

[15] UNI EN 12504-2, Testing concrete in structures: Determination of rebound number, 2012.

[16] ASTM C805/C805M - 13a, Standard test method for rebound number of hardened concrete, ASTM International, West Conshohocken, PA, 2013.

[17] ASTM D5873-14, Standard test method for determination of rock hardness by rebound hammer method, ASTM International, West Conshohocken, PA, 2014.

[18] ACI Committee 228.1R-95, In-place methods to estimate concrete strength, 2003.

[19] Piovesan, R. et al., Stones of the facade of the Sarno Baths, Pompeii: A mindful construction choice. Journal of Cultural Heritage, 2019. DOI: 10.1016/j.culher.2019.04.010.

[20] Cinque, A. \& Irollo, G., Il "Vulcano di Pompei": nuovi dati geomorfologici e stratigrafici. Il Quaternario, Italian Journal of Quaternary Sciences, 17(1), pp. 101116, 2004.

[21] Santoro, S. (ed.), Pompei. Insula del centenario (IX, 8). Vol. 1: Indagini diagnostiche geofisiche e analisi archeometriche, Studi e Scavi. Nuova serie, Ante Quem: Bologna, 2007.

[22] Kastenmeier, P., Di Maio, G., Balassone, G., Boni, M., Joachimski, M. \& Mondillo, N., The source of stone building materials from the Pompeii archaeological area and its surroundings. Periodico di Mineralogia, Special Issue, pp. 39-58, 2010.

[23] UNI EN 1926, Natural stone test methods: Determination of compression strength, 2000 . 